\title{
Editorial Welcome
}

Welcome to the third volume and year of the publication of Cosmopolitan Civil Societies): an Interdisciplinary e-journal. The journal is produced out of the UTS Cosmopolitan Civil Societies Research Centre (CCS), established in 2007 with a cross faculty, interdisciplinary, social science focus that is empirically informed and policy oriented. The research focus of CCS stresses community engagement, and values both scholarly and societal impact. CCS foregrounds civil society, both through and beyond its relationships with economy and the state. It specifically frames its research orientation within a sense of a globalising, increasingly cosmopolitan world, recognizing the penetration of those processes in the local world. It foregrounds a particular recognition of cultural diversity, emphasizing both Indigenous and immigrant communities; it carries a broad commitment to issues of equality, including gender and disability dimensions, and it is concerned to explicate the interpenetration of human and environmental sustainability.

This issue of the journal presents papers that reflect the broad range of interdisciplinary interest of this journal. Interrogating the notion of identities and diversity from multiple, dynamic, perspectives is central to the cosmopolitan research project, as is the notion of agency. All the papers in this volume make contributions to this debate.

John Rule draws on his research into the changing nature of inner city community development work to reflect on the professional identity of the community worker that emerged in the 1970s and is linked to other emergent identities - the resident activist, social activist and community activist. He argues that it is still possible to identify areas for productive engagement and development in community development and community building in inner city environments through what he calls practising place.

Louise Katz also looks at the issue of identity via the narratives of popular culture that resonate in the imagination to inform the ways in which we understand and interpret the world. The identity of an entire people, she argues, can be rendered down so that those social groups come to seem more spectral than human, through either misrecognition or a lack of acknowledgment. To support this argument Katz investigates traditional anti-Semitism, in which the Jew is viewed as a vampiristic agent of decay, and the way in which the Arab presence becomes 'spectralised' in contemporary Israel/Palestine. Her argument is that it is through imagination and storytelling that we continually create and recreate the realities we must then inhabit.

Paul Spoonley and Carina Meares make an important contribution on the urban spatial aspects of the super-diversity that emerges from large scale immigrant business development in their article on ethnic precincts in Auckland, New Zealand's key gateway immigrant city. Their article looks at the ethnic identity of place and the politics underlying it. Focussing on the impact of immigrant entrepreneurs in transformation of the cityscape Auckland, Spoonley and Meares explore the way that neo-liberalism and laissez-faire attitudes constrain attempts 
to develop, brand and market certain areas of immigrant entrepreneur concentration in the city as ethnic precincts. Unlike the Australian experience of ethnic precincts, reported in the first issue of this journal, there is an unwillingness of central and local government to brand spaces and places of immigrant business concentration with the ethnic iconography and identity of specific immigrant groups. At the same time, ethnic community networks fight for influence and recognition in Auckland, one of the world's most cosmopolitan cities.

The remainder of the papers in this issue concentrate on different aspects of the politics of the ethnic Chinese presence and issues related to their agency, diversity and identity in Australian society. Significant flows of Chinese immigration to Australia dated from the 1850s and continued strongly in the second half of the nineteenth century. The White Australian policy, bedrock of Australian Federation, not only constrained new inflows of Chinese immigrants but also made life very difficult for those Chinese immigrants resident in Australia. It was not until the White Australia policy was formally and finally abolished by the Whitlam Labor Government that large scale Chinese immigration could resume. In recent decades an emphasis on skilled and business migration has seen the arrival of large numbers of highly educated young Chinese and older entrepreneurs.

Andrew Jakubowicz reviews the history of “The Chinese” as Australia’s Other and explores the complex and multiple layers of engagement of the Chinese in the Australian political system. Interrogating the meaning(s) of "The Chinese”, Jakubowicz looks at many dimensions of Chinese politics in Australia, including their involvement in a wide range of political parties. He argues that a critical understanding of Chinese politics in Australia helps us understand the challenges of a globalised post-multicultural politics.

The point of departure of Jen Tsen KWOK's article is the ethnic, socio-economic and political diversity of the contemporary urban Chinese immigrant population in Australia, who demonstrate patterns of spatial and economic concentration in Australian cities. The social dynamics of the Chinese community in these areas of concentration are continuously refashioned by new arrivals increasing the diversity of the Australian Chinese immigrant community that stands in sharp contradistinction with homogenous, racialised constructions of Chineseness. Utilising the theoretical frame of urban regime theory, Kwok explores the politics of Chinese Australian community groups and associations in Brisbane, demonstrating how transnational political tensions highlight the diversity and potential fragility of diasporic interdependence within ethnic Chinese communities

FENG Chongyi is also interested in Chinese community politics in Australia and takes as a point of departure the diversity of the political values, attitudes or beliefs of the Chinese communities in Australia. He argues that there is no such a thing as inherent "cultural values" or "national values" that differentiate "the Chinese" politically from the mainstream Australian society. He concludes that there is a growing trend among Chinese migrants, old and new, to be voluntarily involved in a political resocialisation after settling in Australia whereby previous illiberal values are transformed to universal values conducive to multicultural democracy. 
Jia GAO looks at Chinese politics in Australia through the prism of the law and the legal system and is interested in the political agency of Chinese immigrants using the law to fight in the Courts for their rights. The validity of the White Australia policy was challenged in the colonial courts, a fact often ignored. Since the White Australia policy was abolished, Gao argues, the Chinese in Australia have never shied away from taking various legal actions, citing instances where Chinese immigrants have successfully won the right stay in Australia through a series of legal battles.

Finally, Chek LING, in a non-refereed contribution, draws on the experience of 50 years of Australian settlement to provide a personal reflection on what it is to be Chinese in Australia today.

Jock Collins, Professor of Social Economics Co-Director Cosmopolitan Civil Societies

31 March 2011 